\title{
Relationship of Opioid Prescriptions to Physical Therapy Referral and Participation for Medicaid Patients with New-Onset Low Back Pain
}

\author{
Anne Thackeray, PhD, Rachel Hess, MD, Josette Dorius, RN, Darrel Brodke, MD, \\ and Julie Fritz, $P h D$
}

Introduction: Physical therapy (PT) early in the management of low back pain (LBP) is associated with reductions in subsequent health care utilization and LBP-related costs. The objectives of this study were to 1) Examine differences among newly consulting patients with LBP who received a PT referral and those who did not, 2) examine differences between patients who participated in PT to those who did not, and 3) compare the impact of a PT referral and PT participation on LBP-related health care utilization and costs over 1 year.

Methods: This was a retrospective cohort study using electronic medical records and claims data. Participants were 454 Medicaid enrollees with new LBP consultations (mean age, 40.4 years; SD = $12.0 ; 70 \%$ women). Outcomes included advanced imaging, injections, emergency department visits, opioid prescriptions, surgery and LBP-related costs. Variables associated with a PT consult, PT participation, and subsequent outcomes were evaluated with multivariate models.

Results: A total of 251 (55\%) participants received a PT consult within 7 days of the index LBP visit and 81 (19\%) participated in PT. The odds of a PT consult were increased if patients were prescribed non-steroidal anti-inflammatories $(\mathrm{aOR}=1.81 ; 95 \%$ confidence interval $[\mathrm{CI}], 1.0$ to $3.27 ; P=.05)$ or muscle relaxers (adjusted odds ratio $[\mathrm{aOR}]=2.24 ; 95 \% \mathrm{CI}, 1.03$ to $4.87 ; P=.04)$. Whereas tobacco users and individual with multiple comorbidities were less likely to receive a PT consult $(\mathrm{aOR}=0.52 ; 95 \% \mathrm{CI}, 0.20$ to 0.91$)$ and $0.42(95 \%$ CI, 0.23 to 0.78), respectively). Odds of participating in PT were higher for patients receiving an radiograph at baseline (odds ratio $[\mathrm{OR}]=2.63 ; 95 \% \mathrm{CI}, 1.25$ to 5.53$)$ or having multiple comorbidities $(\mathrm{OR}=2.96 ; 95 \% \mathrm{CI}$, 1.20 to 7.20). The odds of receiving an opioid prescription over the year following the index visit reduced with a PT consult (aOR $=0.65 ; 95 \% \mathrm{CI}, 0.43$ to 1.00$)$ and with PT participation $(\mathrm{aOR}=0.47$; $95 \% \mathrm{CI}, 0.24$ to 0.92$)$. No differences in LBP related costs over 1 year were noted between any of the groups.

Conclusions: Among Medicaid recipients with new-onset LBP, the index provider's prescription and imaging decisions and patient demographics were associated with PT referrals and participation. A referral to PT and subsequent PT participation was associated with reduced opioid prescriptions during follow-up. There was no difference in overall LBP-related health care costs. (J Am Board Fam Med 2017;30:784-794.)

Keywords: Back Pain, Health Services, Opioid Analgesics, Physical Therapy Modalities

Low back pain (LBP) is costly and the process of care is highly variable. ${ }^{1,2}$ The choice of management strategy employed for new-onset LBP impacts downstream health care utilization and costs.

This article was externally peer reviewed.

Submitted 18 February 2017; revised 24 May 2017; accepted 26 May 2017.

From the Department of Physical Therapy and Athletic Training (AT, JF), Health System Innovation and Research (AT, RH), General Internal Medicine (RH), University of Utah Health Plans (JD), and the Department of Orthopaedics (DB, JF), University of Utah, Salt Lake City, UT.
Primary care guidelines recommend education and physical therapy (PT) as first-line approaches in uncomplicated cases of LBP and generally discour-

\section{Funding: none.}

Prior Presentations: Data were presented as a poster at the Center for Health Services Training and Research Summer Institute in Boston, MA in 2016 and a platform presentation at the American Physical Therapy Combined Sections Meeting in Anaheim, CA in 2016.

Conflict of interest: none declared.

Corresponding author: Anne Thackeray, PhD, 520 Wakara

Way, SLC, UT 84108 (E-mail: a.thackeray@utah.edu). 
age imaging. ${ }^{3,4}$ Care consistent with these guidelines is a cost-effective way to improve patient outcomes. $^{5,6}$ In particular, PT early in the management of LBP is associated with reductions in subsequent health care utilization and LBPrelated costs. ${ }^{7-9}$

Studies supporting PT early in the management of LBP have not examined the frequency with which PT was recommended, only the frequency with which it was received. The proportion of patients receiving early PT is low, between $7 \%$ and $20 \%^{7,8,10}$, but the proportion of patients referred is not known. Identifying only patients who have participated in PT fails to account for the impact of the referral itself. The referral potentially represents a provider-patient interaction about the nature of the LBP and prognosis. Improved outcomes among PT cohorts may represent of a combination of patient compliance with the PT recommendation and a provider's beliefs about the nature and severity of the LBP. To understand the impact of PT on subsequent health care utilization and costs, we need to understand the factors influencing a PT consult, factors influencing subsequent patient participation in PT, and how these factors are associated with health care visits and costs.

These questions are of particular importance for Medicaid enrollees. Since the Affordable Care Act, states are seeing an increase in Medicaid enrollment, subsequent costs, and spending. ${ }^{11}$ The presentation of Medicaid enrollees is notably more complex than privately insured individuals. These individuals generally have worse overall health, twice the rate of mental health disorders, and higher risk of opioid abuse. ${ }^{12} \mathrm{LBP}$ is more common among Medicaid enrollees and the primary reason for visiting the emergency department (ED). ${ }^{12,13}$ Given this picture, it is not surprising that Medicaid enrollees are 3 times more likely to develop chronic LBP. ${ }^{14}$ Understanding factors influencing patterns of health care in this population, particularly decisions made early in the course of care, is an important step in developing cost-effective solutions.

The purpose of this study was to examine the differences between newly consulting Medicaid patients with LBP (1) who received a PT referral and patients who did not receive a referral, and (2) patients with a referral who participated in PT and patients not participating. Second, we compared the impact of a PT referral and of subsequent PT participation on LBP-related health care utilization and costs for the 1-year period following the index visit.

\section{Methods \\ Data Source}

The study sample was identified from claims data of enrollees in the University of Utah Health Plans (UUHP) Medicaid Managed Care Plan, "Healthy U." UUHP is a nonprofit health insurance provider and subsidiary of University of Utah Heath (UUH) covering approximately 43,000 Medicaid beneficiaries in the region. The Healthy $\mathrm{U}$ program transitioned is a fully at-risk capitation payment as of January 1, 2013. In preparation for this transition, providers agreed to a LBP management model aligned with clinical guidelines. This included the use of imaging only in the presence of "red flags" and early referral to PT. While providers agreed to this model, they were not incentivized for adherence nor were they restricted in the use of any procedure or treatment. Electronic medical records (EMRs) were matched with Healthy U member numbers to capture LBP-related health care utilization and consult records. The Institutional Review Board at the University of Utah approved the study.

\section{Sample}

Participants were newly consulting patients between the ages of 17 to 60 with a primary care provider visit containing a LBP-related ICD-9 code between January 1, 2012 and December 31, 2013. Primary care visits included family practice, obstetrics and gynecology, internal medicine, or office-based urgent care within UUH. A newly consulting patient was defined as having no claims related to LBP in the previous 90 days. To ensure 1-year followup, patients were required to have continuous enrollment in Healthy U 1-year following the entry visit date. Exclusion criteria were aimed at limiting the sample to individuals with musculoskeletal pain as the source of the LBP claim (Appendix). We excluded those with ICD-9 codes indicating a possible nonmusculoskeletal cause for LBP including urinary tract infection, kidney or gallbladder stones. Additional exclusion criteria included red flag conditions that may require urgent management (neoplasm, fracture, infection, or cauda equina syndrome). We also excluded conditions likely to impact the ability to access outpatient 
services including hemiplegia, paraplegia, quadriplegia, or wheelchair dependence, and end stage renal disease.

\section{Grouping Variables}

Patients with a PT consult in the EMR within 7 days of the index visit were considered to have received a PT referral related to the LBP visit. PT participants were defined as individuals with a PT consult and a PT visit within 90 days of the consult. Nonparticipants also had a PT consult but no record or charges for PT.

\section{Demographic and Co-Morbidity Variables}

Age, sex, and health plan were collected from Healthy $\mathrm{U}$ and EMR data. Comorbid conditions were recorded from ICD-9 codes for all claims recorded in the year following the entry visit. We used comorbidities listed in the EMR to compute the Charlson Co-Morbitiy Index (CCI). ${ }^{15}$ The CCI measures comorbid disease status and is the most commonly used measure of multimorbidity in relation to patient function and quality of life. ${ }^{16}$ Higher scores on the CCI indicate greater multimorbidity. We also identified comorbid conditions likely to influence LBP-related prognosis or health care utilization, including mental health conditions, chronic pain, substance use disorders, smoking status, and obesity (Appendix). Opioid prescription use 90 days before the index visit (yes/no) was identified through claims data.

\section{Process Variables}

Procedures associated with the index visit included imaging, additional referrals, and prescription medications. Imaging at index was identified by CPT codes on the date of the index visit. Index orders (placed within 7 days of index visit) included referrals for specialty spine care (eg, surgery, neurology, orthopedics), advanced imaging, spinal injections, or neurodiagnostic studies. Index prescriptions were any prescriptions filled within 14 days following the index date.

\section{Health Care and Cost Outcomes}

Health care services and costs were evaluated in the 1 -year period following the index visit. Services were treated as binary variables and included (1) radiographs of lumbo-pelvic region, (2) advanced imaging (magnetic resonance imaging $[\mathrm{MRI}]$ or computed tomography [CT] scan of lumbo-pelvic region), (3) lumbar surgical procedure, (4) epidural injection of the lumbar spine or sacroiliac joint, (5) ED visit related to a LBP ICD-9 code, and (6) opioid prescription. Total LBP-related costs represent allowed costs for all claims associated with a LBP-related ICD-9 code during the year following the entry visit.

\section{Data Analyses}

Data were analyzed using SPSS v21.0 (IBM Corporation, Armonk, NY). Descriptive statistics were evaluated using means (standard deviations), medians (quartiles), or frequency counts (percentages) for each participation group. Univariate associations were examined between groups. Variables were entered into a multivariate logistic regression model in blocks and included in the regression if univariate associations were significant at $P \leq .15$. Sequential blocks included age and sex, comorbidities, imaging and specialty care referrals, and finally, prescriptions at index visit.

$\chi^{2}$ and multivariate logistic regression models were used to identify the impact of participation and PT referral on LBP-related health care utilization for the 1-year period following the index visit. Due to the skewed nature of cost data, comparisons of health costs between groups were examined using generalized linear regressions with $\log$ link function and gamma distribution.

\section{Results}

Of 505 adult Medicaid enrollees identified as newly consulting for LBP, 454 patients initiated services within primary care (Figure 1). Of these, 215 (47\%) had a referral for PT. The sample was predominantly female $(71 \%)$ with a mean age of 40.4 (SD = 12.0) years. Demographic characteristics and comorbidities for the sample are presented in Table 1. Thirty-nine cases $(8.6 \%)$ were missing data for prescription history. Missing patterns seemed random (Little's Missing Completely at Random [MCAR] test; $P=.13$ ) and no adjustments were made.

\section{PT Participation}

Of the 215 patients referred to PT, 81 (37\%) attended at least 1 LBP-related PT visit within 90 days of referral. The mean number of days from the index visit to PT was $21.3(\mathrm{SD}=21.7)$ and the 
Figure 1. Participants within a Medicaid Managed Care Low-Back Pain Cohort presenting to primary care (January 1, 2012 to December 31, 2013).

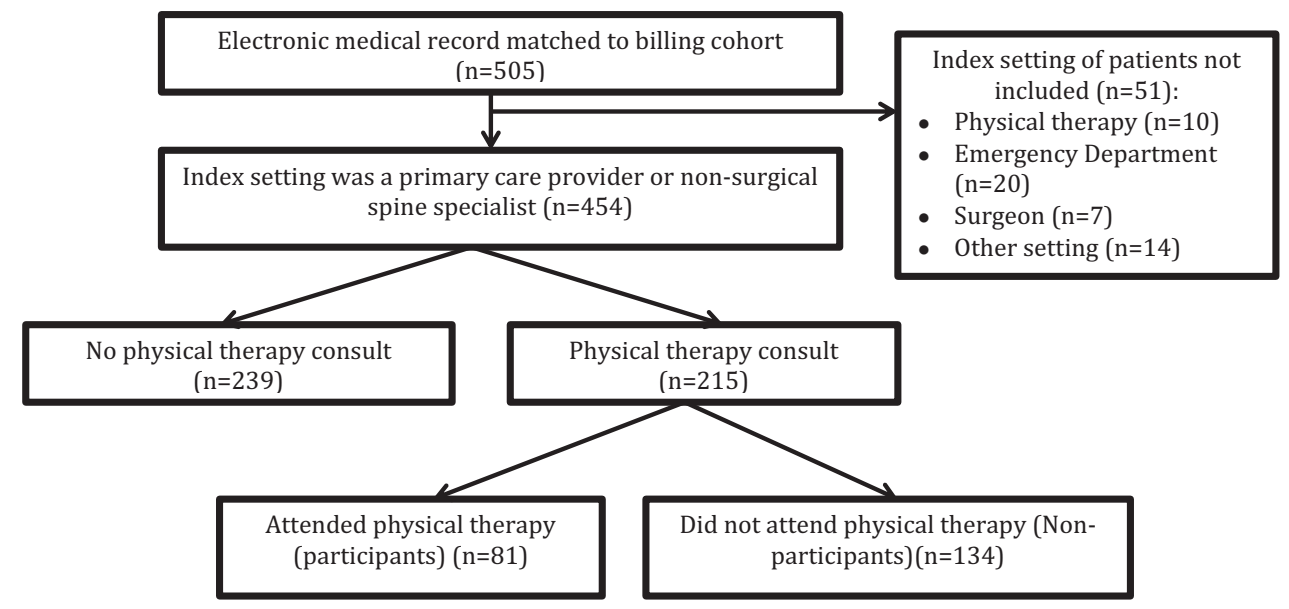

median number of PT visits was 4.0 (Interquartile range $[\mathrm{IQR}]=5.0)$.

\section{Predictors of Receiving a PT Consult}

Younger age, receiving an radiograph, or receiving a prescription for non-steroidal anti-inflammatories (NSAIDs) or muscle relaxers were each positively associated with receiving a PT consult (Table 1). Variables negatively associated with receiving a PT consult included tobacco use, chronic pain, depression, 2 or more comorbidities on the CCI, and receiving a referral for specialty care or advanced imaging.

Using these factors, a multivariate logistic regression model was built to predict receiving a PT consult (Table 2). Assumptions of the model were met and no data transformations were performed. Decisions made at the index visit significantly influenced receiving a PT consult (Table 2). In particular, the odds of a PT consult were increased if patients were prescribed NSAIDs (adjusted odds ratio $[\mathrm{aOR}]=1.81 ; 95 \%$ confidence interval $[\mathrm{CI}]$, 1.0 to $3.27 ; P=.05)$ or muscle relaxers $(\mathrm{aOR}=$ 2.24; $95 \%$ CI, 1.03 to $4.87 ; P=.04$ ). If there was a referral to specialty care or advanced imaging; however, the odds of a PT consult were 25 times less likely (aOR $=0.03 ; 95 \% \mathrm{CI}, 0.01$ to $0.09 ; P \leq .01)$. While comorbidities as a block improved the model, the most significant individual contributors were tobacco use and multiple comorbidities. The adjusted odds of receiving a PT consult for tobacco users was 0.52 (95\% CI, 0.20 to $0.91 ; P=.02)$ and for individuals with multiple comorbidities was 0.42 (95\% CI; 0.23 to $0.78 ; P=.01$ ).
The most significant improvement in model fit was the addition of imaging procedures and referrals for specialty care or advanced imaging (Table 2). These variables improved the explained variance in PT consults from 0.17 to $0.36(P \leq .01)$. However, the total explained variance of the model for predicting a consult to PT was only moderate (Nagelkerke $R^{2}=0.39$ ).

\section{Predictors of PT Participation}

Univariate predictors of PT participation included age, having $\mathrm{x}$-rays at the index visit, and having 1 or more comorbidities on the CCI. Conversely, multiple orders at baseline and opioid prescription history were associated with nonparticipation (Table 1). In the multivariate model, age and sex accounted for a small amount of variance in PT participation (Nagelkerke $R^{2}=0.07$; Table 3). The 4 additional predictors statistically improved model fit $\left(\chi^{2}(\mathrm{df} 4)=26.3 ; P \leq .01\right)$ with a modest improvement in explained variance (Nagelkerke $\left.R^{2}=0.23\right)$.

After controlling for age and sex, participation in PT was predicted by having 2 or more comorbidities $(\mathrm{aOR}=2.96 ; 95 \% \mathrm{CI}, 1.20$ to $7.20 ; P=.02)$ and receiving an radiograph at the index visit $(\mathrm{aOR}=2.63 ; 95 \% \mathrm{CI}, 1.25$ to $5.53 ; P=.01)$. Reduced odds of PT participation were associated with multiple orders (eg, specialty referral, advanced imaging) placed in conjunction with the PT consult $(\mathrm{aOR}=0.28 ; 95 \% \mathrm{CI}, 0.11$ to $0.70 ; P=$ $.01)$ and a history of opioid use ( $\mathrm{aOR}=0.38 ; 95 \%$ CI, $0.17=0.83 ; P \leq .01)$. 
Table 1. Baseline Characteristics of a Medicaid Managed Care Low-Back Pain Cohort Presenting to Primary Care (January 1, 2012 to December 31, 2013)

\begin{tabular}{|c|c|c|c|c|c|c|c|}
\hline \multirow[b]{2}{*}{ Variable } & \multirow[b]{2}{*}{$\begin{array}{l}\text { All Patients } \\
(\mathrm{n}=454)\end{array}$} & \multicolumn{3}{|c|}{ Consult Status } & \multicolumn{3}{|c|}{$\begin{array}{c}\text { Participation Status Among Those with } \\
\text { Consults }\end{array}$} \\
\hline & & $\begin{array}{l}\text { PT Consult } \\
(\mathrm{n}=215)\end{array}$ & $\begin{array}{l}\text { No PT Consult } \\
\quad(\mathrm{n}=239)\end{array}$ & $P$-Value & $\begin{array}{c}\mathrm{PT} \\
(\mathrm{n}=81)\end{array}$ & $\begin{array}{c}\text { No PT } \\
(\mathrm{n}=134)\end{array}$ & $P$-value \\
\hline \multicolumn{8}{|l|}{ Demographic variables } \\
\hline $\begin{array}{l}\text { Age (years), mean } \\
\text { (SD) }\end{array}$ & $40.4(12.0)$ & $37.3(11.7)$ & $43.1(11.6)$ & .00 & $39.9(12.02)$ & $35.8(11.3)$ & .01 \\
\hline Female & $321(70.7 \%)$ & $160(74.4 \%)$ & $161(67.4 \%)$ & .12 & $57(70.4 \%)$ & $103(76.9 \%)$ & .33 \\
\hline Depression & $138(30.4 \%)$ & $53(24.7 \%)$ & $85(35.6 \%)$ & .01 & $23(28.4 \%)$ & $30(22.4 \%)$ & .33 \\
\hline Chronic pain & $129(28.4 \%)$ & $40(18.6 \%)$ & $89(37.2 \%)$ & .00 & $12(14.8 \%)$ & $28(20.9 \%)$ & .29 \\
\hline Obesity & $102(22.5 \%)$ & $44(20.5 \%)$ & $58(24.3 \%)$ & .37 & $17(21.0 \%)$ & $27(20.1 \%)$ & 1.00 \\
\hline Smoker & $106(23.3 \%)$ & $33(15.3 \%)$ & $73(30.5 \%)$ & .00 & $11(13.6 \%)$ & $22(16.4 \%)$ & .70 \\
\hline Charlson CCI & & & & .00 & & & \\
\hline $\mathrm{CCI}<2$ & $245(54.0 \%)$ & $148(68.8 \%)$ & $97(40.6 \%)$ & & $45(55.6 \%)$ & $103(76.9 \%)$ & $<.01$ \\
\hline CCI 2 to 3 & $130(28.6 \%)$ & $48(22.3 \%)$ & $82(34.3 \%)$ & & $28(34.6 \%)$ & $20(14.9 \%)$ & \\
\hline $\mathrm{CCI}>3$ & $79(17.4 \%)$ & $19(8.8 \%)$ & $60(25.1 \%)$ & & $8(9.9 \%)$ & $11(8.2 \%)$ & \\
\hline $\begin{array}{l}\text { Prior opioid } \\
\text { prescription (within } \\
90 \text { days of index) }\end{array}$ & $99(21.8 \%)$ & $42(21.8 \%)$ & $57(25.7 \%)$ & .40 & $9(12.3 \%)$ & $33(27.5 \%)$ & .02 \\
\hline \multicolumn{8}{|c|}{ Procedure variables at index visit } \\
\hline $\mathrm{X}$-ray at index visit & $75(16.5 \%)$ & $44(20.5 \%)$ & $31(13.0 \%)$ & .04 & $24(29.6 \%)$ & $20(14.9 \%)$ & .01 \\
\hline MRI at index visit & $2(0.4 \%)$ & 0 & $2(0.8 \%)$ & - & 0 & 0 & - \\
\hline Additional orders & $75(16.5 \%)$ & $35(16.3 \%)$ & $40(16.7 \%)$ & 1.00 & $8(9.9 \%)$ & $27(20.1 \%)$ & .06 \\
\hline $\begin{array}{l}\text { Consult to Specialty } \\
\text { care }\end{array}$ & $61(13.4 \%)$ & $3(1.4 \%)$ & $58(24.3 \%)$ & .00 & $0(0 \%)$ & $3(2.2 \%)$ & .30 \\
\hline $\begin{array}{l}\text { Consult for advanced } \\
\text { imaging }\end{array}$ & $19(4.2 \%)$ & $2(0.9 \%)$ & $16(7.1 \%)$ & .001 & $1(1.2 \%)$ & $1(0.7 \%)$ & 1.00 \\
\hline Opioid prescription & $113(24.9 \%)$ & $50(25.95)$ & $63(28.4 \%)$ & .58 & $14(19.2 \%)$ & $36(30.0 \%)$ & .13 \\
\hline NSAID prescription & $96(21.1 \%)$ & $56(29.05)$ & $40(18.0 \%)$ & .01 & $20(27.4 \%)$ & $36(30.0 \%)$ & .75 \\
\hline $\begin{array}{l}\text { Muscle relaxant } \\
\text { prescription }\end{array}$ & $51(11.2 \%)$ & $35(18.1 \%)$ & $16(7.2 \%)$ & .001 & $9(12.3 \%)$ & $26(21.7 \%)$ & .12 \\
\hline
\end{tabular}

CCI, Co-Morbitiy Index; MRI, magnetic resonance imaging; NSAID, non-steroidal anti-inflammatory; PT, physical therapy; SD, Standard Deviation.

\section{LBP-Related Health Care Utilization and Costs}

Within 90 days of the index visit, $136(30 \%)$ patients received additional care. PT comprised the majority $(60 \%)$ of additional health care. Outside of primary care or PT, $20 \%$ of patients consulted a nonsurgical specialist, $13 \%$ receiving advanced imaging, and $7 \%$ consulted a surgical spine specialist.

During the year following the index visit, an opioid prescription was the most commonly used intervention $(42 \%)$ followed by $\mathrm{x}$-rays $(17 \%)$ and ED visits (13\%; Table 4). Receiving a PT consult did not increase or decrease the odds of advanced imaging or ED use, but was associated with a reduction in opioid prescriptions (Supplemental Table 1). The strongest predictor of an opioid prescription after the index visit was an opioid prescription at baseline. Even after controlling for baseline opioid prescriptions, age, sex, tobacco use, and depression, individuals who received a PT consult at baseline were less likely to receive an opioid prescription during the year following the index visit $(\mathrm{aOR}=0.65 ; 95 \% \mathrm{CI}$, 0.43 to $1.00 ; P=.04)$.

Crude odds ratios for additional health care between participant groups demonstrated increased advanced imaging for PT participants, but decreased ED and opioid use (Tables 4 and Supplemental Table 1). After adjusting for confounding variables, the differences in ED use were no longer apparent but the reduction in odds for an opioid prescription during followup persisted. The adjusted odds of a PT participant receiving an opioid prescription in the year following the index visit were 0.47 (95\% CI, 0.24 to $0.92 ; P=.03$ ). No 
Table 2. Predictors of Receiving a Physical Therapy Consult within a Medicaid Managed Care Low-Back Pain Cohort Presenting to Primary Care (January 1, 2012 to December 31, 2013): Multivariate Logistic Regression Modeling Blocks and Parameter Estimates for Predictors

\begin{tabular}{|c|c|c|c|c|c|}
\hline Predictor Variable & B & aOR $(95 \% \mathrm{CI})$ & $\begin{array}{l}P \text {-Value for } \\
\text { Predictor }\end{array}$ & $\begin{array}{l}\text { Nagelkerke } \\
R^{2}\end{array}$ & $\begin{array}{l}P \text {-Value for } \\
\text { Block }\end{array}$ \\
\hline Age (years) & -0.02 & $0.98(0.96$ to 1.00$)$ & .17 & 0.07 & .00 \\
\hline Sex (female) & -0.15 & $0.86(0.52$ to 1.4$)$ & .55 & & \\
\hline Comorbidities & & & & 0.17 & .00 \\
\hline Depression & -0.23 & $0.79(0.48$ to 1.32$)$ & .33 & & \\
\hline Chronic pain & -0.32 & $0.73(0.43$ to 1.25$)$ & .25 & & \\
\hline Obesity & -0.22 & $0.80(0.47$ to 1.36$)$ & .41 & & \\
\hline Tobacco use & -0.65 & $0.52(0.30$ to 0.91$)$ & .02 & & \\
\hline 2 or more on the Charlson & -0.86 & $0.42(0.23$ to 0.78$)$ & .01 & & \\
\hline Index procedures & & & & 0.36 & .00 \\
\hline $\mathrm{X}$-ray & 0.59 & $1.81(0.97$ to 3.36$)$ & .06 & & \\
\hline $\begin{array}{l}\text { Referral for specialty care or advanced } \\
\text { imaging }\end{array}$ & -3.47 & $0.03(0.01$ to 0.09$)$ & .00 & & \\
\hline Index prescriptions & & & & 0.39 & .00 \\
\hline NSAID drugs & 0.60 & $1.81(1.00$ to 3.27$)$ & .05 & & \\
\hline Muscle relaxers & 0.81 & $2.24(1.03$ to 4.87$)$ & .04 & & \\
\hline
\end{tabular}

aOR, adjusted odds ratio; CI, confidential interval; CCI, Co-Morbidity Index; NSAID, non-steroidal anti-inflammatory.

adjustments were made for advanced imaging due to the small number of non-PT participants receiving advanced imaging. The odds of a PT participant receiving advanced imaging were 6 times higher than non-PT participants (odds ratio $[\mathrm{OR}]=6.21 ; 95 \% \mathrm{CI}, 1.95$ to $19.61 ; P=\leq .01)$.

Average LBP-related costs over the course of 1 year for Medicaid participants were \$442 (95\% CI, 335 to 549). Higher costs were associated with tobacco use, depression, females, and older participants. No significant differences in cost were noted between patients based on PT consult status or PT participation (Supplemental Table 2).

\section{Discussion}

A number of studies have examined the impact of participation in PT on health outcomes and costs, but have not accounted for provider recommendations or consults. ${ }^{7,8,17}$ In this cohort of Medicaid recipients in a single health system, we examined an intermediate step between a primary care provider visit and PT participation, a PT consult. Both patient characteristics and procedural decisions (prescriptions and imaging) were associated with patients receiving a PT consult and subsequently participating in PT. We did not find any associations between prior opioid use and receiving a PT

Table 3. Predictors of Physical Therapy Participation within a Medicaid Managed Care Low-Back Pain Cohort Presenting to Primary Care and Receiving a Physical Therapy Consult (January 1, 2012 to December 31, 2013): Multivariate Logistic Regression Modeling Blocks and Parameter Estimates for Predictors

\begin{tabular}{|c|c|c|c|c|c|}
\hline Predictor Variable & B & aOR $(95 \% \mathrm{CI})$ & $\begin{array}{l}P \text {-Value for } \\
\text { Predictor }\end{array}$ & $\begin{array}{c}\text { Nagelkerke } \\
R^{2}\end{array}$ & $\begin{array}{l}P \text {-Value for } \\
\text { Block }\end{array}$ \\
\hline Age & -0.01 & $0.99(0.96$ to 1.02$)$ & .73 & 0.07 & .00 \\
\hline Sex (female) & -0.10 & $0.90(0.45$ to 1.80$)$ & .77 & & \\
\hline $\mathrm{X}$-ray at index & 0.97 & $2.63(1.25$ to 5.53$)$ & .01 & 0.23 & .00 \\
\hline Multiple orders at index & -1.28 & $0.28(0.11$ to 0.70$)$ & .01 & & \\
\hline 2 or more comorbidities & 1.08 & $2.96(1.20$ to 7.20$)$ & .02 & & \\
\hline Prior opioid prescription (within 90 days) & -0.89 & $0.38(0.17$ to 0.83$)$ & .02 & & \\
\hline
\end{tabular}

aOR, adjusted odds ratio; CI, confidential interval. 
Table 4. Healthcare Utilization within a Medicaid Managed Care Low-Back Pain Cohort Presenting to Primary Care (January 1, 2012 to December 31, 2013) by Physical Therapy (PT) Consult Status and by PT Participation Status

\begin{tabular}{|c|c|c|c|c|c|c|c|}
\hline $\begin{array}{l}\text { Care Beyond } \\
\text { Index Visit }\end{array}$ & $\begin{array}{l}\text { All Patients } \\
(\mathrm{n}=454)\end{array}$ & $\begin{array}{c}\text { PT Consult } \\
(\mathrm{n}=215)\end{array}$ & $\begin{array}{l}\text { No PT Consult } \\
\quad(\mathrm{n}=271)\end{array}$ & $P$-Value & $\begin{array}{l}\text { PT Participants } \\
\quad(\mathrm{n}=81)\end{array}$ & $\begin{array}{l}\text { Non-PT Participants } \\
\quad(\mathrm{n}=134)\end{array}$ & $P$-Value \\
\hline $\mathrm{X}$-rays & $79(17.4 \%)$ & $37(17.2 \%)$ & $42(17.6 \%)$ & 1.00 & $13(16.0 \%)$ & $24(17.9 \%)$ & .85 \\
\hline $\begin{array}{l}\text { Advanced } \\
\text { imaging }\end{array}$ & $48(10.6 \%)$ & $17(7.9 \%)$ & $31(13.0 \%)$ & .09 & $13(16.0 \%)$ & $4(3.0 \%)$ & .00 \\
\hline Spinal injection & $22(4.8 \%)$ & $6(2.8 \%)$ & $16(6.7 \%)$ & .08 & $4(4.9 \%)$ & $2(1.4 \%)$ & .20 \\
\hline Surgery & $3(0.7 \%)$ & 0 & $3(1.3 \%)$ & .25 & 0 & 0 & - \\
\hline $\begin{array}{l}\text { Emergency } \\
\text { department }\end{array}$ & $59(13 \%)$ & $33(15.3 \%)$ & $26(10.9 \%)$ & .17 & $7(8.6 \%)$ & $26(19.4 \%)$ & .05 \\
\hline $\begin{array}{l}\text { Opioid Rx during } \\
\text { followup }\end{array}$ & $192(42.3 \%)$ & $78(40.4 \%)$ & $114(51.4 \%)$ & .03 & $21(28.8 \%)$ & $57(47.5 \%)$ & .01 \\
\hline
\end{tabular}

Number in bold represent significant between group differences. PT, Physical Therapy; Rx, prescription.

consult. However, a PT consult alone was associated with reduced odds of an opioid prescription after the index visit. PT participation further reduced the odds of an opioid prescription during followup. This held true even after controlling for the prescription of opioids at baseline. Understanding the causative factors for this outcome will require mixed methods designs gathering both patient and provider perspectives and random experimentation of these interventions. Although constrained by the limits of a single health system, these results highlight the impact of the initial provider visit and provide a foundation for future work understanding patient and provider beliefs surrounding the initial primary care visit for LBP.

It is unclear why receiving a PT consult is associated with a decrease in opioid prescriptions, this is a potentially important finding in light of the current opioid epidemic. ${ }^{18}$ Early prescription of opioids for acute LBP is associated with longer work disability and worse functioning. ${ }^{19-21}$ Once prescribed opioids, individuals with more mental and physical health comorbidities or increased use of the ED are at higher risk for opioid misuse. ${ }^{22,23}$ The negative association between opioid prescription and PT participation noted in this study should be explored further to determine whether PT early in the management of LBP could mitigate these patterns of opioid use. Providing a PT consult in place of an opioid prescription is a reasonable alternate strategy for pain management and improved function ${ }^{24}$, particularly in this population of Medicaid enrollees.

Prior studies suggest patients participating in PT early in the management of LBP have lower odds for subsequent health care use and surgery. ${ }^{7,8,25}$ Results from the current study were mixed. With a smaller sample, few participants received spinal injections and only $3(0.7 \%)$ had surgery limiting our ability to detect differences between these groups. Costs were constrained by limiting the study to a single health system and payer. Accounting for PT consult status differentiated this study from prior studies examining only patients who received PT. In prior studies, it is unknown whether patients were recommended PT and simply did not attend. Patients with a consult to PT represent a unique and important subset as the consult may represent a reflection of a provider's values and subsequent communication with the patient. ${ }^{26-28}$ Recommending PT provides reassurance to patients who their LBP is best managed with physical activity and is in line with advice to stay active. This in itself has potential to change cost and health care use..$^{5,29,30}$

Patients receiving a radiograph at baseline or a prescription of nonopioid medications were more likely to participate in PT. Most guidelines do not recommend radiographs for new-onset LBP. ${ }^{31,32}$ However, practitioners report using imaging as a way to provide reassurance and enhance the provider-patient relationship. ${ }^{33}$ This assumption has not been supported ${ }^{34}$, although patients report increased satisfaction when they receive imaging. ${ }^{35}$ Having this expectation met may increase compliance with provider recommendations such as PT.

Following through on a PT recommendation was associated with reduced ED use and fewer opioid prescriptions. Rates of advance imaging however, were higher. This finding was unexpected 
and inconsistent with previous studies. ${ }^{7,8}$ Patients are influenced by the education and information provided by a physical therapist ${ }^{36}$ and the results may reflect a unique culture in the health system studied. Alternately, this may represent a sampling error as advanced imaging represented only $8 \%$ of individuals receiving a PT consult.

Our population may be unique in its distribution of women $(70 \%)$. Similar LBP studies report a slightly greater distribution of women to men seeking care for LBP, however, the proportion of women in these studies was around $55 \%$ female. ${ }^{7,8}$ Within our region, $66 \%$ of Medicaid recipients are female and thus represent a greater portion of the base study population. ${ }^{37}$ So although it is reasonable that women represented a larger portion of participants in our study, caution is recommended in generalizing the results to male Medicaid recipients as management strategies are known to differ for men versus women. ${ }^{9,38}$

There are some other limitations that must be considered when reviewing these results. Our findings are ones of association rather than causation limiting the ability to direct change in current practice. The associations identified, however, provide a foundation for future research. Medical decision making is complex. The elements driving clinical decisions are not well understood nor always represented as discrete data in an EMR. Patient presentation is also complex, particularly in a Medicaid population with higher rates of comorbidities and mental health disorders. ${ }^{39,40}$ It is unclear how this presentation is affecting diagnostic certainty and subsequent treatment recommendations. ${ }^{41}$ Our referral rates for PT were higher than those in a national survey of mixed insurance status, but our specialty referrals, imaging, and prescriptions patterns were similar. ${ }^{42}$ This pattern suggests primary care provider behaviors in this study are consistent with routine practice within the United States and are not dramatically influenced by the fact these are Medicaid recipients. Finally, there remains some risk of misclassification. We categorized patients by referral status based on electronic referrals. It is possible, providers made a recommendation for PT without placing a consult in the EMR. Our initial dataset included all claims data for PT with or without a consult. The proportion of PT recipients identified by claims data without a consult was $3 \%$ suggesting the influence of this misclassification is likely low.
Future work is needed to identify factors influencing provider decision making and patient follow-through. Linking providers' knowledge of guidelines and willingness to follow guideline recommendations with management decisions would increase our understanding of the decision to place a PT consult. Similarly, exploring the culture and communication strategies of the physical therapists could elucidate factors influencing increased rates of advanced imaging. Although many providers are familiar with treatment guidelines, there may be uncertainty in the applicability of guidelines for individual patients, particularly when the diagnosis is uncertain. ${ }^{43,44}$ This uncertainty can drive up rates of low value diagnostic testing. For a capitated system to save costs, understanding the factors surrounding compliance with clinical practice guidelines will be critical.

These results also suggest more work is needed to understand patient behaviors. Only $38 \%$ of patients referred to PT attended. We know little about what influences adherence to a PT referral. Qualitative research with these patients could provide much needed insights into how patients perceive PT, implications of a PT referral, and patient expectations.

\section{Conclusions}

Among Medicaid enrollees with new-onset LBP, nearly half $(47 \%)$ of patients seeing a primary-care provider were referred to PT. Referrals to PT were more likely among individuals with fewer comorbidities and nonsmokers. Providers prescribing NSAIDs or muscle relaxers were more likely to place a PT consult. Conversely, providers placing a specialty care or advanced imaging consult were less like to refer to PT. Patients most likely to participate in PT after receiving a consult had multiple comorbidities, received a radiograph at the index visit, but did not receive additional orders or have a history of opioid use. Both a PT referral and PT participation reduced the odds an opioid prescription during followup. PT participation had a mixed impact on other health care use and no difference on overall costs.

To see this article online, please go to: http://jabfm.org/content/ 30/6/784.full.

\section{References}

1. Birkmeyer JD, Reames BN, McCulloch P, Carr AJ, Campbell WB, Wennberg JE. Understanding of re- 
gional variation in the use of surgery. Lancet 2013; 382:1121-1129.

2. Martin BI, Turner JA, Mirza SK, Lee MJ, Comstock BA, Deyo RA. Trends in health care expenditures, utilization, and health status among US adults with spine problems, 1997-2006. Spine (Phila Pa 1976) 2009;34:2077-2084.

3. Koes BW, van Tulder M, Lin CW, Macedo LG, McAuley J, Maher C. An updated overview of clinical guidelines for the management of non-specific low back pain in primary care. Eur Spine J 2010;19: 2075-2094.

4. Casazza BA. Diagnosis and treatment of acute low back pain. Am Fam Physician 2012;85:343-350.

5. Lin CW, Haas M, Maher CG, Machado LA, van Tulder MW. Cost-effectiveness of general practice care for low back pain: a systematic review. Eur Spine J 2011;20:1012-1023.

6. Fritz JM, Kim M, Magel JS, Asche CV. Cost-effectiveness of primary care management with or without early physical therapy for acute low back pain: Economic evaluation of a randomized clinical trial. Spine (Phila Pa 1976) 2017;42:285-290.

7. Fritz JM, Brennan GP, Hunter SJ, Magel JS. Initial management decisions after a new consultation for low back pain: Implications of the usage of physical therapy for subsequent health care costs and utilization. Arch Phys Med Rehabil 2013;94:808-816.

8. Childs JD, Fritz JM, Wu SS, et al. Implications of early and guideline adherent physical therapy for low back pain on utilization and costs. BMC Health Serv Res 2015;15:150.

9. Fritz JM, Brennan GP, Hunter SJ. Physical therapy or advanced imaging as first management strategy following a new consultation for low back pain in primary care: Associations with future health care utilization and charges. Health Serv Res 2015;50: 1927-1940.

10. Fritz JM, Kim J, Thackeray A, Dorius J. Use of physical therapy for low back pain by medicaid enrollees. Phys Ther 2015;95:1668-1679.

11. Rudowitz R, Snyder L. Medicaid enrollment \& spending growth: FY 2015 \& 2016. Washington, DC; 2015.

12. Ghate SR, Haroutiunian S, Winslow R, McAdamMarx C. Cost and comorbidities associated with opioid abuse in managed care and Medicaid patients in the United Stated: A comparison of two recently published studies. J Pain Palliat Care Pharmacother 2010;24: 251-8.

13. Braden JB, Russo J, Fan MY, et al. Emergency department visits among recipients of chronic opioid therapy. Arch Intern Med 2010;170:1425-1432.

14. Shmagel A, Foley R, Ibrahim H. Epidemiology of chronic low back pain in US adults: National Health and Nutrition Examination Survey 2009-2010. Arthritis Care Res (Hoboken) 2016;68:1688-1694.
15. Quan H, Sundararajan V, Halfon P, et al. Coding algorithms for defining comorbidities in ICD-9-CM and ICD-10 administrative data. Med Care 2005;43: 1130-1139.

16. Huntley AL, Johnson R, Purdy S, Valderas JM, Salisbury C. Measures of multimorbidity and morbidity burden for use in primary care and community settings: A systematic review and guide. Ann Fam Med 2012;10:134-141.

17. Fritz JM, Childs JD, Wainner RS, Flynn TW. Primary care referral of patients with low back pain to physical therapy: Impact on future healthcare utilization and costs. Spine (Phila Pa 1976) 2012;37:2114-2121.

18. Manchikanti L, Helm S 2nd, Fellows B, et al. Opioid epidemic in the United States. Pain Physician 2012; 15(3 Suppl):ES9-E38.

19. Ashworth J, Green DJ, Dunn KM, Jordan KP. Opioid use among low back pain patients in primary care: Is opioid prescription associated with disability at 6-month follow-up? Pain 2013;154: 1038-1044.

20. Franklin GM, Stover BD, Turner JA, Fulton-Kehoe D, Wickizer TM, Disability Risk Identification Study C. Early opioid prescription and subsequent disability among workers with back injuries: The Disability Risk Identification Study Cohort. Spine (Phila Pa 1976) 2008;33:199-204.

21. Webster BS, Verma SK, Gatchel RJ. Relationship between early opioid prescribing for acute occupational low back pain and disability duration, medical costs, subsequent surgery and late opioid use. Spine (Phila Pa 1976) 2007;32:2127-2132.

22. Cochran BN, Flentje A, Heck NC, et al. Factors predicting development of opioid use disorders among individuals who receive an initial opioid prescription: Mathematical modeling using a database of commercially-insured individuals. Drug Alcohol Depend 2014;138:202-208.

23. Kobus AM, Smith DH, Morasco BJ, et al. Correlates of higher-dose opioid medication use for low back pain in primary care. J Pain 2012;13:1131-1138.

24. Dowell D, Haegerich T, Chou R. CDC guidelines for prescribing opioids for chronic pain-United States 2016. MMWR Recomm Rep 2016;65:1-49.

25. Gellhorn AC, Chan L, Martin B, Friedly J. Management patterns in acute low back pain: The role of physical therapy. Spine (Phila Pa 1976) 2012;37: 775-782.

26. Freburger JK, Holmes GM, Carey TS. Physician referrals to physical therapy for the treatment of musculoskeletal conditions. Arch Phys Med Rehabil 2003;84:1839-1849.

27. Darlow B, Dean S, Perry M, Mathieson F, Baxter GD, Dowell A. Acute low back pain management in general practice: Uncertainty and conflicting certainties. Fam Pract 2014;31:723-732.

28. Darlow B, Fullen BM, Dean S, Hurley DA, Baxter GD, Dowell A. The association between health care 
professional attitudes and beliefs and the attitudes and beliefs, clinical management, and outcomes of patients with low back pain: A systematic review. Eur J Pain 2012;16:3-17.

29. Lin CW, Haas M, Maher CG, Machado LA, van Tulder MW. Cost-effectiveness of guideline-endorsed treatments for low back pain: A systematic review. Eur Spine J 2011;20:1024-1038.

30. Traeger AC, Hübscher M, Henschke N, Moseley GL, Lee H, McAuley JH. Effect of primary carebased education on reassurance in patients with acute low back pain: Systematic review and metaanalysis. JAMA Intern Med 2015;175:733-743.

31. Davis PC, Wippold FJ 2nd, Brunberg JA, et al. ACR appropriateness criteria on low back pain. J Am Coll Radiol 2009;6:401-407.

32. Chou R, Qaseem A, Snow V, et al. Diagnosis and treatment of low back pain: A joint clinical practice guideline from the American College of Physicians and the American Pain Society. Ann Intern Med 2007; 147:478-491.

33. Baker R, Lecouturier J, Bond S. Explaining variation in GP referral rates for $x$-rays for back pain. Implement Sci 2006;1:15.

34. Rolfe A, Burton C. Reassurance after diagnostic testing with a low pretest probability of serious disease: Systematic review and meta-analysis. JAMA Intern Med 2013;173:407-416.

35. Kendrick D, Fielding K, Bentley E, Kerslake R, Miller P, Pringle M. Radiography of the lumbar spine in primary care patients with low back pain: Randomised controlled trial. BMJ 2001;322:400405 .

36. Darlow B, Dowell A, Baxter GD, Mathieson F, Perry M, Dean S. The enduring impact of what clinicians say to people with low back pain. Ann Fam Med 2013;11:527-534.

37. Distribution of Nonelderly Adults with Medicaid by Gender. The Henry J. Kaiser Family Foundation. 2015. Available from: http://kff.org/medicaid/stateindicator/distribution-by-gender-4/. Accessed May 8, 2017.

38. Hollingshead NA, Matthias MS, Bair MJ, Hirsh AT. Impact of race and sex on pain management by medical trainees: A mixed methods pilot study of decision making and awareness of influence. Pain Med 2015;16:280-290.

39. Adelmann PK. Mental and substance use disorders among Medicaid recipients: Prevalence estimates from two national surveys. Adm Policy Ment Health 2003;31:111-29.

40. Decker SL, Kostova D, Kenney GM, Long SK. Health status, risk factors, and medical conditions among persons enrolled in Medicaid vs uninsured low-income adults potentially eligible for Medicaid under the Affordable Care Act. JAMA 2013;309: 2579-2586.

41. Forrest CB, Nutting PA, von Schrader S, Rohde C, Starfield B. Primary care physician specialty referral decision making: patient, physician, and health care system determinants. Med Decis Making 2006;26: 76-85.

42. Mafi JN, McCarthy EP, Davis RB, Landon BE. Worsening trends in the management and treatment of back pain. JAMA Intern Med 2013;173:15731581.

43. Corbett M, Foster N, Ong BN. GP attitudes and self-reported behaviour in primary care consultations for low back pain. Fam Pract 2009;26:359-364.

44. Heneghan C, Glasziou P, Thompson M, et al. Diagnostic strategies used in primary care. BMJ 2009; 338:b946. 


\begin{tabular}{|c|c|c|}
\hline & Diagnosis & ICD-9 Code \\
\hline \multirow[t]{15}{*}{ Conditions included } & Low back pain & 720.2 \\
\hline & & 721.3 \\
\hline & & 722.1 \\
\hline & & 722.52 \\
\hline & & 722.73 \\
\hline & & 722.93 \\
\hline & & $724 . x$ \\
\hline & & 739.3 \\
\hline & & 739.4 \\
\hline & & 756.11 \\
\hline & & 756.12 \\
\hline & & $846 . x$ \\
\hline & & 847.2 \\
\hline & & 847.3 \\
\hline & & 847.9 \\
\hline \multirow{6}{*}{$\begin{array}{l}\text { Red flag conditions requiring } \\
\text { urgent management } \\
\text { (excluded) }\end{array}$} & Urinary tract infection & 599.0 \\
\hline & Kidney or gallbladder stones & 592.x 574.x \\
\hline & Malignant neoplasm & 140.x to $209 . x$ \\
\hline & $\begin{array}{l}\text { Fracture or stress fracture of spine or } \\
\text { pelvis }\end{array}$ & $\begin{array}{c}805 . x \text { to } 809 . x \\
820 . x \text { to } 821 . x \\
733.13 \text { to } 733.15 \text { or } 733.96 \text { to } 733.98\end{array}$ \\
\hline & Osteomyelitis & $733 . x$ \\
\hline & Cauda equina syndrome & $344.6 x$ \\
\hline \multirow{2}{*}{$\begin{array}{l}\text { Conditions likely to impact } \\
\text { the ability to access } \\
\text { outpatient services } \\
\text { (excluded) }\end{array}$} & $\begin{array}{l}\text { Hemiplegia, paraplegia, quadriplegia or } \\
\text { wheelchair dependence }\end{array}$ & $\begin{array}{l}344.0 \mathrm{x} \text { to } 344.1 \mathrm{x} \\
344.8 \mathrm{x} \text { to } 344.9 \mathrm{x} \\
438.2 \mathrm{x} \text { to } 438.5 \mathrm{x}\end{array}$ \\
\hline & End-stage renal disease & $\begin{array}{c}403.01 \\
403.91 \\
585.5 \mathrm{x} \text { to } 585.6 \mathrm{x} \\
\mathrm{V} 45.11\end{array}$ \\
\hline \multirow[t]{5}{*}{ Comorbidities } & Mental health conditions & $\begin{array}{l}\text { 296. to 298.x } \\
300 . x \\
301 . x \\
308 . x \\
309 . x \\
311 . x\end{array}$ \\
\hline & Chronic pain & $338 . x$ \\
\hline & Substance use disorders & $\begin{array}{c}\text { 291.x } \\
\text { 303.x to } 304 . \mathrm{x} \\
305.0 \\
305.2 \mathrm{x} \text { to } 305.9 \mathrm{x} \\
648.3\end{array}$ \\
\hline & Smoking status & $\begin{array}{l}305.1 \\
V 15.82 \\
649.0 x\end{array}$ \\
\hline & Obesity & $278 . x$ \\
\hline
\end{tabular}

